\title{
AN AUDIT OF PATTERN OF PATIENTS' PRESENTATION AT THE PERIODONTICS CLINIC OF THE UNIVERSITY COLLEGE HOSPITAL, IBADAN.
}

\author{
Olanrewaju I'. Opeodu, Modupeola O. Arowojolu', S.O. Gbadebo ${ }^{2}$, and Titilola S. Ibiyemi ${ }^{3}$
}

1. Department of Preventive Dentistry, University College Hospital, Ibadan, Nigeria, West Africa.

2. Department of Restorative Dentistry, University College Hospital, Ibadan.

3. Department of Oral and Maxillofacial Surgery, University College Hospital, Ibadan.

Correspondence:

Dr. Olanrewaju I. Opeodu

Department of Preventive Dentistry,

University College Hospital,

Ibadan, Nigeria.

Telephone: +2348055217682

E-Mail: opeodulanre@yahoo.com

\begin{abstract}
Objectives: This study is aimed at assessing the various reasons why patients present at the periodontics clinic of the University College Hospital, Ibadan.

Materials and Methods: A six months retrospective review of patients treated in the periodontics clinic of the University College Hospital, Ibadan was conducted. Case file records were retrieved and information on patients' bio-data, occupation and their various presenting complaint during their first consultation at the clinic were reviewed. Three hundred patients were seen in the clinic during the period under review but records of four of them were incomplete and were therefore excluded from the study. The association between the gender of the patients and their various initial presenting complaints was assessed using chi-square tests, p set at $(<0.05)$.

Results: Records of two hundred and ninety-six patients were reviewed comprising of 150 males and 146 female (M/F, 1:1). Out of these patients, only eighty-four (28.4\%) had been coming for regular check-up while the remaining $71.6 \%$ reported with various complaints. Majority $(45.3 \%)$ presented with pain of which there were slightly more females than males $(M / F=1: 1.1)$. Gum bleeding and poor oral hygiene were other reasons why patients presented at the clinic. The younger age groups were noticed to be more frequent at the clinic on routine basis than the older ones during the period under review.

Conclusion: The finding of this study further confirmed that majority of people only seek dental care to alleviate their pain. We therefore suggest that efforts should be intensified towards public enlightenment, as prevention is better and cheaper than cure.
\end{abstract}

Keywords: Audit, pattern, pain, presentation.

\section{INTRODUCTION}

Dental care utilization can be defined as the percentage of the population who access dental services over a specified period of time ${ }^{1}$. Measures of actual dental care utilization describe the percentage of the population who have seen a dentist at different time intervals. Dental disease is a serious public health problem with universal distribution and affecting all age groups ${ }^{2}$. However, despite this universal distribution, only a few seek dental care. Thus a wide gap is created between the actual dental needs of the population and the demand for dental care ${ }^{3}$.

Although dentists agree that regular dental visits are essential for maintaining good oral health, national studies in the United States of America estimate that only $41-50 \%$ of all Americans visit the dentist each year ${ }^{4}$. In Nigeria, Savage and Arowojolu reported that $24(31.58 \%)$ of the 76 subjects investigated perceived it as being normal for them to bleed from the gum ${ }^{5}$. Therefore, they have no reason to seek dental care for this obvious pathological condition. The study by Savage and Arowojolu further reported that 164 $(82.4 \%)$ of their subjects claimed not to notice bleeding from their gum and believed that they do not have gum disease but dental examination revealed that none of the subjects seen had healthy periodontal status. Amongst those that admitted to having noticed the bleeding from their gum, just about half admitted that it is a sign of gingival disease yet none of them sought 
for dental care ${ }^{5}$. This observation in Nigeria is in line with that of Ainamo and Ainamo ${ }^{6}$.

There are reports that dental patients only visit the dentist when in pain and never bother to return for follow-up in most cases ${ }^{7}$. To the best of our knowledge, only few studies have been carried out to either confirm or dispute this claim in Nigeria ${ }^{8}$. We therefore embarked on this retrospective study to assess various reasons why patients present at the periodontics clinic of the University College Hospital, Ibadan.

\section{MATERIALS AND METHODS}

Two hundred and ninety-six patients that were seen and treated for various clinical conditions between the months of April and September 2007 at the periodontics clinic of the University College Hospital, Ibadan were studied. Case file records were retrieved and information on patients' demographic data, occupation and their various presenting complaints during their first appointment were retrieved. The association between the gender of the patients and their various initial presenting complaints was assessed using chi-square tests, p set at $(<0.05)$.

\section{RESULTS}

One hundred and fifty $(50.7 \%)$ of the cases reviewed were males while One hundred and forty-six (49.3\%) were females. Classifying the patients into the various classes according to the socio-economic strata devised by Famuyiwa et al. (1998) ${ }^{9}$, it was discovered that majority of the patients seen in the clinic during the period under review were civil servants constituting $50.3 \%$. Sixty-four $(21.6 \%)$ of the two hundred and ninety-six patients were students while the semi-skilled were the least represented as just twelve $(4.1 \%)$ were seen during the period under review (Table 1).

\begin{tabular}{|l|c|c|}
\hline Social strata & Number of patients & Percentage \\
\hline Givil Servant & 149 & 50.3 \\
\hline *Student & 64 & 21.6 \\
\hline Executives & 38 & 128 \\
\hline Unskilled & 33 & 11.1 \\
\hline Semi Skilled & 12 & 4.1 \\
\hline Total & 296 & 100 \\
\hline
\end{tabular}

(* Modification of the classification by Famminsa et al., 1998)

Table 1: Distribution of patients by Ocaupation

Figure 1 shows that 84 (28\%) of the patients seen at the periodontics clinics came specifically for routine professional prophylaxis while $212(72 \%)$ were referred from other clinics in the dental centre for professional prophylaxis.

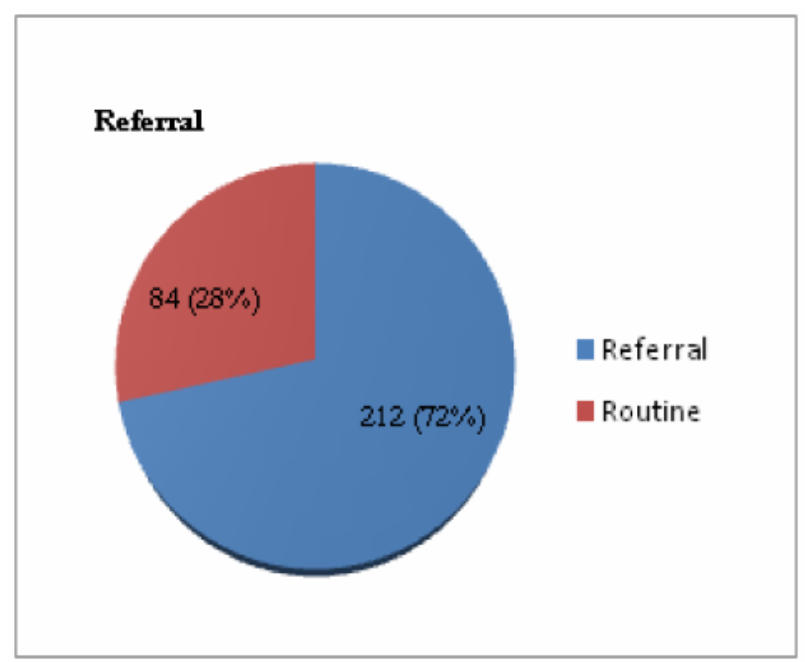

Figure 1: Distribution of patients based on referral and routine prophylaxis

One hundred and thirty-four $(45.3 \%)$ of the patients during the period under review presented with pain and of this number, sixty-four $(47.8 \%)$ were males while 70 were females representing $52.2 \%$ of the patients presenting with pain (Table 2).

\begin{tabular}{|l|c|c|c|}
\hline Gender & Pain Present & Pain Absent & Total \\
\hline Male & $64(47.8)$ & $86(53.1)$ & 150 \\
\hline Female & $70(52.2)$ & $76(46.9)$ & 146 \\
\hline Total & $134(45.3)$ & $162(54.7)$ & $296(100)$ \\
\hline
\end{tabular}

Table 2: D istribution of patien ts presenting with pain according to gender

$$
X^{2}=1.023 \quad P=0.312 \quad P>0.05
$$

Twenty-nine patients presented with complaint of gum bleeding while brushing while 267 did not present with such complaint (Figure 2).

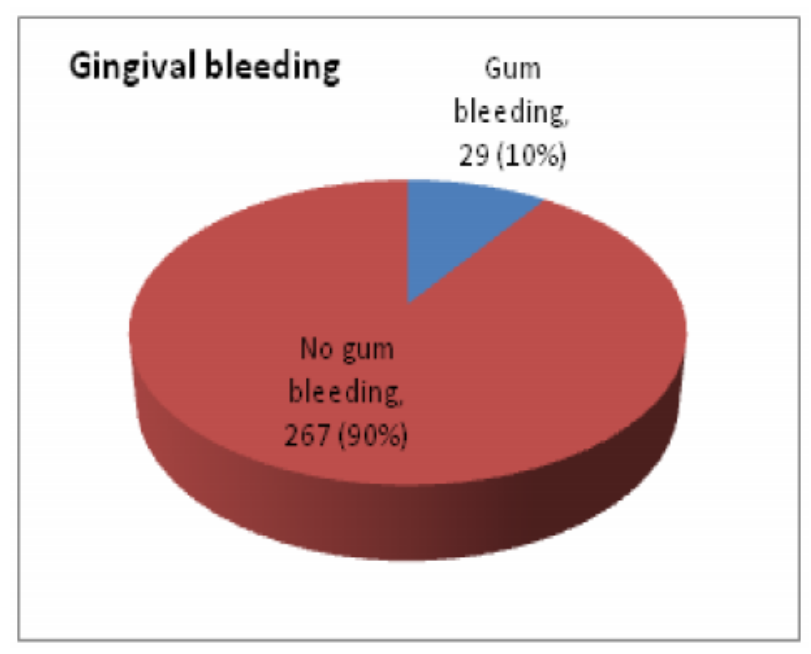

Figure 2: Distribution of patients according to presenting complaint of gum bleeding 
Figure 3 below shows that $87(29 \%)$ presented with a complaint of poor oral hygiene while 209 (71\%) considered their oral hygiene to be good enough.

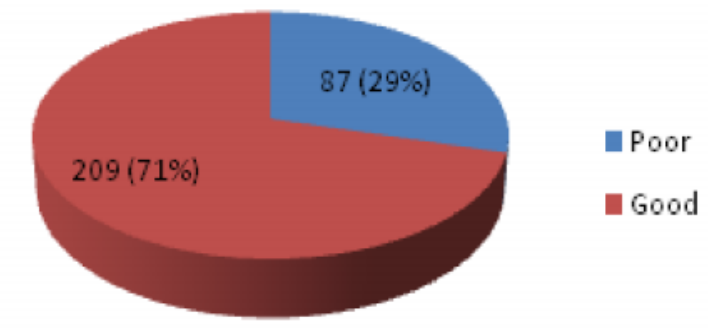

Figure 3: Distribution of patients based on oral hygiene

\begin{tabular}{|l|l|l|l|}
\hline Age Group & Yes & No & Total \\
\hline $16-30$ (I) & $35(42.2 \%)$ & $83\left(39^{\circ} \%\right.$ & $118(39.9 \%)$ \\
\hline $31-45$ (II) & $22(26.5 \%)$ & $54\left(25.4^{\circ} \%\right)$ & $76\left(25.7^{\circ} \%\right)$ \\
\hline $46-60$ (III) & $18(21.7 \%)$ & $45(21.1 \%)$ & $63\left(21.3^{\circ} \%\right.$ \\
\hline$>60$ (IV) & $8(9.6 \%)$ & $31\left(14.5^{\circ} \%\right)$ & $39\left(13.2^{\circ} \%\right)$ \\
\hline Total & $83(100 \%)$ & $213(100 \%)$ & $296(100.1 \%)$ \\
\hline
\end{tabular}

Table 4: Distribution of rate of dental visitation by patients according to their age groups

Table 4 shows that people in age-group I (42.2\%) presented more in the clinic for regular dental visits followed by age-group II (26.5\%) and age-group III while age-group IV $(9.6 \%)$ were the least seen on regular bases.

\section{DISCUSSION}

Civil Servants formed the bulk of the patients seen during the period under review with a total of 149 $(50.3 \%)$ followed by students $64(21.6 \%)$ and the executives which comprises of bankers, engineers, doctors, etc. Less of unskilled/uneducated people were seen and this could be partly due to the fact that the clinic is in an urban environment, with tertiary institutions around and educated people forming a greater percentage of the people in the city ${ }^{8}$. This trend can also be linked to the financial status of patients, i.e. those people who are in the middle to high socioeconomic class can afford dental care more than the people of lower class. Some studies have reported that the cost of treatment is a major barrier to the utilisation of dental care and that people with dental insurance visited the dentist more than those without insurance did ${ }^{3,10}$. This retrospective study did not look into the effect of health insurance, which presently covers mainly the civil servants in the federal government employment. This lesser number of people in lower socio-economic class seen during the period under review could however also be due to the low level of dental awareness among the people of lower socio-economic class. This reservation was expressed by Lo when it was observed that underutilization of dental services was mainly due to low level of dental awareness and lack of time and cost of treatment ${ }^{11}$. Furthermore, the result of the present study is in agreement with the findings of Manski and Moeller, who reported that people in higher socioeconomic classes and those that are more educated visit the dentist for preventive care more than the less educated people with lower annual income ${ }^{12}$.

The present study also observed that most patients seen in the periodontics clinic during the period under review were referred from other clinics within the dental centre. This implies that they presented primarily because of other symptoms like pain, tooth mobility, trauma and diagnostic reasons other than for preventive measures. This is also in accordance with Manski and Moeller who concluded in their study that most people reported mainly for diagnostic dental procedures but periodontics and endodontics together accounted for just about $3 \%$ out of the $65 \%$ for diagnostic and preventive procedure in their study ${ }^{12}$.

It was also observed that less people were seen on regular dental visits for prevention of periodontal diseases, which could be due mainly to low level of dental awareness among the populace ${ }^{10,12}$. It could also be due to lack of time by patients because they are busy trying to make an end meet and do not create time to take care of their general health in totality and oral health in particular. This is in contrast to the thinking by the dentists that regular visits are essential for maintaining good oral health ${ }^{4}$. It was also observed that patients in age group I, i.e., age 16-30 years presented in the clinic for regular visit more than the older age groups though not significant statistically $(\mathrm{p}=$ 0.336). This can be partly attributed to the fact that majority of the people in this age group were students, and also the possibility of their being from the higher income earning class. These are strong factors in dental care utilisation $^{10,11,13,14}$. We speculate that this could also be because people of this age group are more conscious of their appearance compared with the older people.

In this present study, slightly higher number of males were seen at the clinic compared to females with a ratio of almost $1: 1$, but more females presented with pain than males though not statistically significant. 
This is similar other other studies where both sexes reported the same pattern for all dental procedures while more females presented with pain than males ${ }^{8}$, 11. Another interesting finding is that $45 \%$ of our patients during this period came because of pain. This goes a long way in confirming the old saying that "pain is the reason why dental patients seek care" which had been confirmed by some studies ${ }^{7,8}$.

Only 29 out of the 296 patients reviewed in this study presented with complaints of gum bleeding. This does not imply that the remaining 267 patients did not have gum bleeding but probably did not think it was necessary to complain about it or did not see it as a pointer to the presence of a periodontal disease. A study reported that some Nigerians even considered it as been normal to bleed from the gum, which informed their not seeking dental care ${ }^{5}$. However, research suggests that bleeding upon the gentle probing of the gingival sulcus may occur even before the changes in colour, form or texture are clinically apparent ${ }^{16}$.

The study also reveals that eighty-seven (29\%) of the patients under review reported their oral hygiene as being poor while the remaining two hundred and nine (71\%) considered their oral hygiene good enough. Clinical examination however revealed that quite a number of them had poor oral hygiene. This shows that there is a wide disparity between the felt need and the perceived need among the population under study.

\section{CONCLUSION}

It is obvious that majority of our patients still visit dental clinic for symptomatic treatment and pain account for the reason why majority present in the clinic. However, some factors such as low level of dental awareness and financial constraint of patient could have led to this pattern of presentation. Nevertheless, the possibility of peoples' negligence of their health, lack of time and fear of undergoing treatment in dental clinic cannot be ruled out.

This suggest that Dental surgeons and dental health workers have not been playing their role adequately in facilitating public enlightenment that people may appreciate the need for regular dental care and make adequate and proper use of the available dental care facilities.

\section{RECOMMENDATION}

$>$ There is need to emphasise more on the preventive aspect of dentistry.
There is need to improve on the present state of dental awareness programmes.

The issue of cost of dental care should be better addressed than it is presently being done, e.g. through the National health insurance scheme program (NHIS).

\section{REFERENCES}

1. Brown L.J. and Lazer V. Dental care utilisation: How saturated is the patient's market? J Am Dent Assoc 1999; 130: 573-580.

2. Allukian M. Dentistry at the crossroads: The future is uncertain: The challenges are many. Am J Public Health 1982; 72: 653-654.

3. Grembowski D., Comrad D. and Milgrom P. Utilisation of dental services in the United States and an insured Population. Am J Public Health 1985; 75: 87-89.

4. Douglas C.W. and Cole K. Utilization of dental services in the US. J Dent Educ 1979 43:223-38.

5. Savage K.O. and Arowojolu M.O. Perception of gingival bleeding by Nigerian. Afr J Med Sci; 26: 91-93.

6. Ainamo J. and Ainamo A. Prevention of Periodontal Diseases in a mixed dentition. Int Dent J 1981; 31:125-132.

7. de Lacerda J.T., Simionato E.M., Peres K.G., Peres M.A., Traebert J. and Marcenes W. Dental pain as the reason for visiting a dentist in a Brazilian adult population. Rev Saúde Pública 2004; 38 (3): $1-6$.

8. Kolude B. and Gbadebo S.O. Orofacial Pain: Pattern of Presentation at Dental Clinic University College Hospital Ibadan. MDS Thesis, 2007.

9. Famuyiwa O.O., Olorunsola D.A. and Derin A. Some family factors in sickle cell anaemia in Lagos, Nigeria. Nig Med Practitioner 1998; 35:70-73.

10. Woosung S., Amid I., Ashley A., James L. Determinants of Dental care visits among lowincome African-American children: J.Am Dent Ass 2007; 138:301-318

11. Lo G.L. The use of Dental services by adult Singaporeans. Singapore Dent J 1993; 18:22-25. 
12. Manski R.J. and Moeller J.F. Use of dental services An analysis of visits, procedures and providers, 1996. J Am Dent Assoc 2002; 133: 167175.

13. Sa'adu and Abdulraheem. Oral health care practice and socio-demographic findings among the physicians in Ilorin, Nigeria. Niger J Med 2003; 12: 211-216.

14. Manski R.J., Moeller J.F. and Maas W.R. Dental services: use, expenditures and sources of payment, 1987. J Am Dent Assoc 1999; 130: 500508.

15. Manski R.J., Edelstein B.L. and Moeller J.F. The impact of insurance coverage on children's dental visits and expenditures, 1996. J Am Dent Assoc 2001; 132: 1137-1145.

16. Newman M.G., Takei H.H and Carranza F.A. Carranza's clinical periodontology. $9^{\text {th }}$ ed., W.B. Saunders co., pp 82. 